radiation by means of a Wilson chamber. Special instruments have to be designed, not only to suit the experiments, but also to fit into the tiny gondola of the balloon. Dr. Cosyns's visit to England was in connexion with this practical side of the preparations. In other fields, Dr. Cosyns plans to investigate, during his ascent, the energy of the total radiation of the sun, in order to determine the calorimetric intensity and the pressure of light of the sun. He will also collect, at various altitudes, samples of air for subsequent analysis. Another practical problem he has to solve is how to enable his balloon to ascend uniformly and slowly, and how to stabilise it eventually at certain heights, his reason being that taking observations during the rapid ascent of the balloon cannot be accurate enough to allow him to draw any final conclusions. of course, once the balloon has reached the stratosphere, it is almost perfectly steady.

\section{Anniversary Meeting of the Royal Society}

IN connexion with the anniversary meeting of the Royal Society which will be held on November 30 , when the medals for the year will be awarded (NATuRE, November 11, p. 740), it is interesting to note that in the allotments of one hundred years ago, November 30, 1833, the Copley medal was not awarded. The Royal medals bore, for the first time, on the obverse, the effigy of King William IV, his Majesty having confirmed and continued the royal grants of George IV, his predecessor. At this anniversary meeting, however, the ten Royal medals adjudged during the lifetime of George IV were available for distribution to the original recipients, or their representatives, who were able to attend, this curious anomaly being due to the circumstance that the dies had never been completed, for reasons beyond the control of the Royal Mint. The names of the selected men of science in the different periods were: Dalton and Ivory (1826); Davy and Struve (1827) ; Encke and Wollaston (1828); Charles Bell and Mitscherlich (1829); Brewster and A. J. Balard (1830). Royal medals were not given in 1831 or 1832. The recipients of the Royal medals for 1833 were (1) Prof. A. de Candolle, of Geneva, for his valuable researches and investigations in vegetable physiology, as detailed in his work "Physiologie Végétale", and (2) Sir John F. W. Herschel for his paper "On the Investigation of the Orbits of Revolv. ing Double Stars", published in the Memoirs of the Royal Astronomical Society. Hersehel was at the time at the Cape of Good Hope. The foregoing medals were presented by the president, H.R.H. the Duke of Sussex.

\section{Action of Radium on Malignant Cells}

During the past year, the Imperial Cancer Research Fund has lost the help of two of its most distinguished officers--Sir Frederic Hallett, who has acted as secretary since the initiation of the scheme, and Sir George Makins, who has for many years been its treasurer and wise counsellor. The report of the director discloses another period of steady progress, mostly, at the moment, in analysing the ways in which radium affects cancer cells. To some degree the influence of radiation is indirect, and the tumour cells are destroyed by their blood supply being cut off owing to the action of the radium on the vessels of the host. But there is also a direct action on the cells themselves, and Dr. Cramer and Mr. Crabtree have been concerned in attempting to analyse this by finding how far the influence of radium is modified by treating the cells with other reagents. If their results do not solve the problem, they show at any rate that it is of unexpected complexity. Thus hydrocyanic acid and low temperatures increase susceptibility to radium, while absence of oxygen increases resistance. Both hydrocyanic acid and anaerobiosis produce increased glycolysis, whence it appears that radium does not act via the glycolytic mechanism. This is corroborated by the discovery that iodoacetic acid and sodium fluoride, which inhibit glycolysis, have no influence on the resistance to radiation. It is also of interest to note that Dr. Ludford's distinction between normal and malignant cells, based on the inability of the latter to segregate trypan blue, has turned out not to be universally applicable, so that it is still true that no one has defined any criterion by which a cell as such may be known to be malignant.

\section{The Study of Insects}

Prof. G. D. H. Carpenter delivered the first part of his inaugural lecture as Hope professor of zoology in the University of Oxford, on November 17. After speaking of the important part played by the study of insects in the solution of some of the chief problems in biology, he went on to deal with questions of parasitism and symbiosis; pointing out that in some cases of close association, both parties are benefited, while in others the entire advantage is enjoyed by one party at the expense of the other. The case was mentioned of the termites, which are enabled to subsist on nitrogen-free material, for example, cotton-wool, in virtue of the Protozoa inhabiting their intestines; these latter having apparently the power of fixing free nitrogen from the air. The importance of insects as carriers of disease was exemplified with many illustrations; and stress was laid on the necessity of a careful study of the habits of the insects concerned, by engineers and others engaged in the control of such maladies as malaria, sleeping-sickness and plague. Without sufficient knowledge, more harm than good may be done by the efforts of health officers. Further points made by Prof. Carpenter included the evolution of the alleged use of 'tools' by burrowing Hymenoptera ; of the 'symbolic marriage gifts' offered by the empid flies; and the function of colours in courtship, as to which some recent views were criticised. Finally, the influence of insects in the production of flowers was adduced as a further illustration of the great part performed by insects in the world of Nature.

\section{Academic Assistance Council}

A meetrong of the Academic Assistance Council, under the presidency of Lord Rutherford, recently reviewed the work accomplished during its first six 